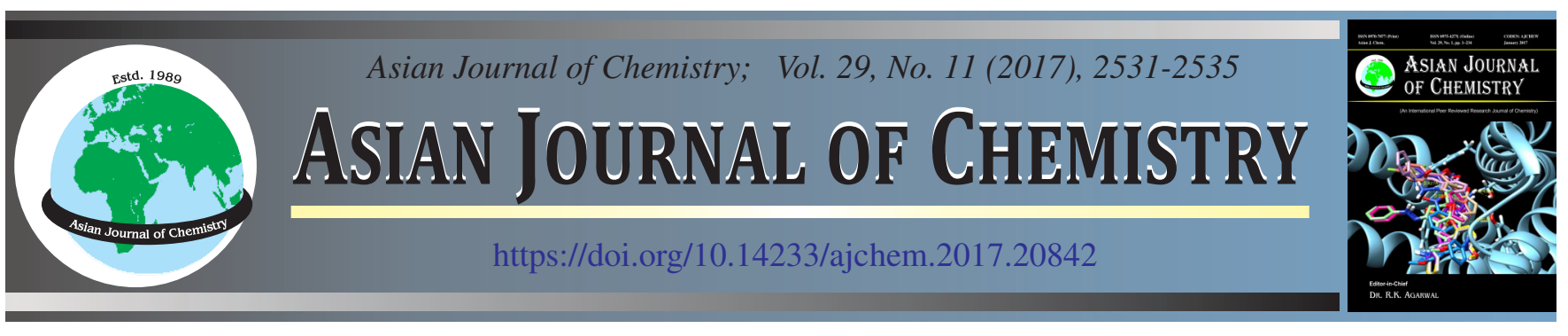

\title{
Variation in Elastic Properties of Holmium Substituted Nickel Copper Zinc Ferrites
}

\author{
B.L. Shinde ${ }^{1}$, L.A. DhALE ${ }^{2}$, K.A. GANURE ${ }^{2}$ and K.S. LOHAR ${ }^{2, *}$
}

${ }^{1}$ Department of Chemistry, Waghire College, Saswad-412 301, India

${ }^{2}$ Department of Chemistry, Shrikrishna Mahavidyalaya, Gunjoti-413 606, India

*Corresponding author: E-mail: kslohar@ rediffmail.com

Received: 7 June 2017;

Accepted: 29 July 2017;

Published online: 29 September 2017;

AJC-18586

\begin{abstract}
Nickel copper zinc ferrites with composition of $\mathrm{Ni}_{0.2} \mathrm{Cu}_{0.2} \mathrm{Zn}_{0.6} \mathrm{Fe}_{2-\mathrm{x}} \mathrm{Ho}_{\mathrm{x}} \mathrm{O}_{4}$ ( $\mathrm{x}=0.0$ to 0.1 in steps of 0.02 ) synthesized by the sol-gel autocombustion method. Sintering temperature of precursors determined using TGA-DTA. XRD patterns indicate that all samples have single phase cubic spinel structure. The IR spectra show two major absorption bands. The microstructures of the prepared samples were studied by SEM and TEM. Elastic moduli and Debye temperature were determined using IR data and XRD data of spinel ferrite samples. The values of Debye temperature, Young's modulus (E), bulk modulus (K) and modulus of rigidity $(\mathrm{G})$ and stiffness constant increased with holmium substitution.
\end{abstract}

Keywords: Ferrite, Holmium, Shearing velocity, Rigidity modulus, Bulk modulus.

\section{INTRODUCTION}

The spinel ferrite structure $\mathrm{MeFe}_{2} \mathrm{O}_{4}$, where Me refers to the metal, can be described as a cubic close-packed arrangement of oxygen atoms, with $\mathrm{Me}^{2+}$ and $\mathrm{Fe}^{3+}$ at two different crystallographic sites. Rare earth element substituted ferrites have important significance and used for numerous industrial applications [1]. The pure and substituted nickel copper zinc ferrites have been the matter of extensive research because of their applications in electronic devices [2]. Nickel copper zinc ferrites with their ease of preparation and versatility for use in wide variety applications are commercially very attractive. Nickel copper zinc ferrites with high permeability and a high Curie temperature have been widely studied for practical and microwave applications [3,4]. Ferrite chip inductors are one of the important components for the latest electronics products such as cellular phones, video cameras, notebook computers, hard and floppy drives [5], etc. The elastic moduli represent the mechanical strength and thermal shock resistance of sample. Mostly ultrasonic pulse transmission method is used to determine the elastic constant [6]. The elastic properties of ferrites determined by using the IR spectroscopy was reported previously [7]. In this study, we presented the variation in elastic properties of holmium substituted nickel copper zinc ferrites.

\section{EXPERIMENTAL}

Holmium substituted nickel copper zinc spinel ferrites doped with holmium, with composition of $\mathrm{Ni}_{0.2} \mathrm{Cu}_{0.2} \mathrm{Zn}_{0.6} \mathrm{Fe}_{2-\mathrm{x}} \mathrm{Ho}_{\mathrm{x}} \mathrm{O}_{4}$
( $x=0.0$ to 0.1 in steps of 0.02 ) were synthesized by the sol-gel auto-combustion method. Analytical reagent grade metal nitrates were used for synthesis. Metal nitrates desired proportion were dissolved in the distilled water, aqueous solution of citric acid ( $1: 3$ ratio metal nitrates: citric acid) added, then the $\mathrm{pH} \approx 7$ of solution adjusted with addition of ammonia solution. The mixed solution was heated on a hot plate with continuous stirring at $90{ }^{\circ} \mathrm{C}$. The viscous gel formed further burnt with glowing flints forming brown-colored precursor. Sintering temperature is determined from TGA/DTA and prepared powders of all the precursor samples were sintered at $500{ }^{\circ} \mathrm{C}$ for $4 \mathrm{~h}$ to obtain the final product.

TGA/DTA of precursors was carried on SDT Q600 V20.9 Build 20. The $\mathrm{X}$-ray powder diffraction with $\mathrm{Cu}-\mathrm{K}_{\alpha}$ radiation $(\lambda=1.5405 \AA$ ) by Phillips X-ray diffractometer (Model 3710) used to study crystal structure. The IR spectra recorded in the range of 200 to $800 \mathrm{~cm}^{-1}$ using Perkin Elmer infrared spectrophotometer. Morphology and structure of the samples were studied on JEOL-JSM-5600 N Scanning Electron Microscope (SEM) and Philips (model CM 200) Transmission Electron Microscope (TEM).

\section{RESULTS AND DISCUSSION}

TG/DTA analysis: The typical TGA/DTA curves of sample ( $\mathrm{x}=0.04$; Fig. 1 ) shows initial weight loss step corresponding to the temperature range of $30-100{ }^{\circ} \mathrm{C}$, (the loss of residual water) and second weight loss step around temperature range of $350-460^{\circ} \mathrm{C}$ (decomposition of unreacted starting citric acid). 


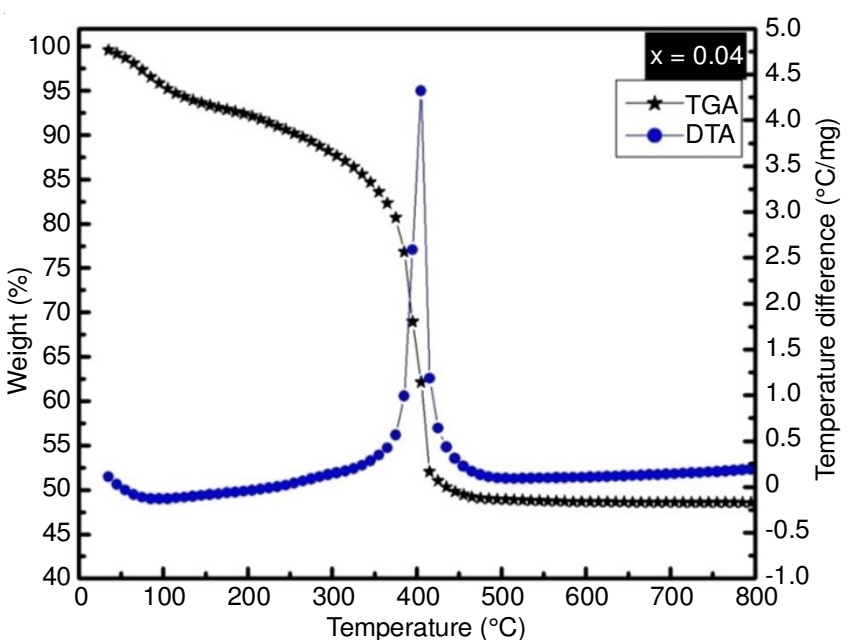

Fig. 1. TGA-DTA plot for precursor $(\mathrm{x}=0.04)$

No weight loss was observed above $460{ }^{\circ} \mathrm{C}$, therefore, all the precursors were sintered at $500{ }^{\circ} \mathrm{C}$ for $4 \mathrm{~h}$ to obtain the final product.

X-ray diffraction: Fig. 2 represents typical XRD pattern for sample $\mathrm{x}=0.06$ confirms the cubic spinel structure of single phase without additional peaks corresponding to any other phases. The lattice constant, particle size and X-ray density were increases with holmium concentration.

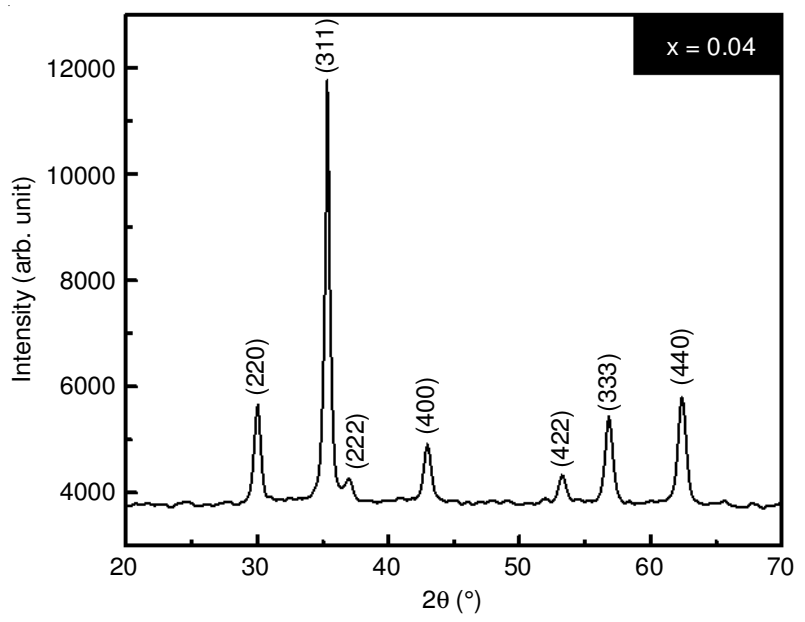

Fig. 2. Typical XRD patterns for sample $\mathrm{x}=0.06$

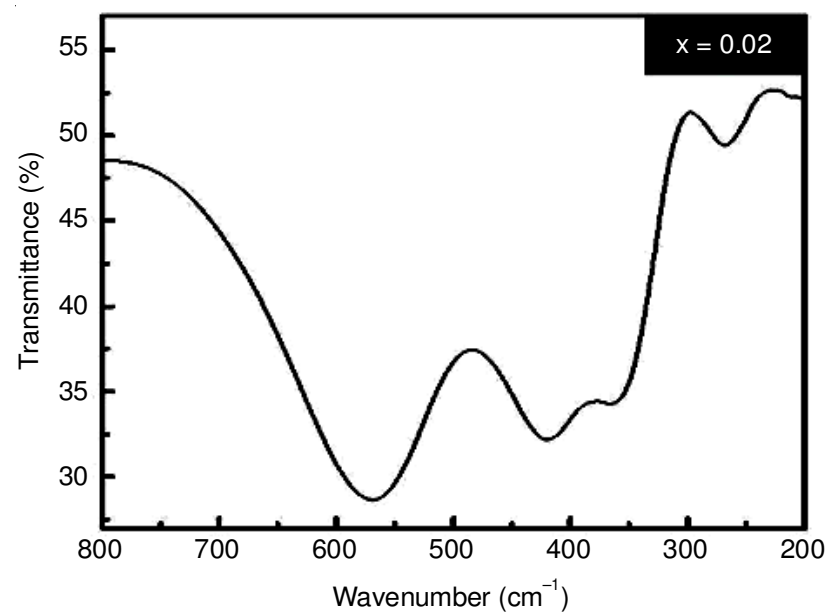

Infrared spectroscopy: Typical IR spectra recorded in the range $200-800 \mathrm{~cm}^{-1}$ of samples $(\mathrm{x}=0.02$ and $\mathrm{x}=0.04)$ are shown in Fig. 3. High frequency bands $\left(574-563 \mathrm{~cm}^{-1}\right)$ assigned to the tetrahedral and low frequency bands $\left(438-364 \mathrm{~cm}^{-1}\right)$ assigned to the octahedral complex.

The force constants corresponding to the tetrahedral and octahedral complexes are calculated by using the standard formulae given below [8]:

$$
\begin{gathered}
K_{t}=7.62 \times M_{1} \times v_{1}^{2} \times 10^{-2} \\
K_{o}=10.62 \times \frac{M_{2}}{2} \times v_{2}^{2} \times 10^{-2}
\end{gathered}
$$

where, $K_{o}$ is the force constant on octahedral site, $K_{t}$ is the force constant on tetrahedral site, $\mathrm{M}_{1}$ molecular weight of tetrahedral site, $\mathrm{M}_{2}$ molecular weight of octahedral site, $v_{1}$ the corresponding center frequency on tetrahedral site, and $v_{2}$ the corresponding center frequency on octahedral site. It is to be noted that force constant ' $\mathrm{K}_{\mathrm{o}}$ ' decreased from $1.19 \times 10^{5}$ to $0.82 \times 10^{5}$ dynes $/ \mathrm{cm}$ and $\mathrm{K}_{\mathrm{t}}$ decreased from $2 \times 10^{5}$ to $1.44 \times$ $10^{5}$ dynes/cm with the substitution of $\mathrm{Ho}^{3+}$ ions.

The average force constant $\mathrm{K}\left[\mathrm{K}=\left(\mathrm{K}_{\mathrm{t}}+\mathrm{K}_{\mathrm{o}}\right) / 2\right]$ is given in Table- 1 . The bond lengths $R_{A}$ and $R_{B}$ have been calculated using the formula given by Gorter [9].

$$
\begin{gathered}
\mathrm{R}_{\mathrm{A}}=\left(\mathrm{u}-\frac{1}{4}\right) \mathrm{a}_{\mathrm{th}} \sqrt{3}-\mathrm{R}_{\mathrm{o}} \\
\mathrm{R}_{\mathrm{B}}=\left(\frac{5}{8}-\mathrm{u}\right) \mathrm{a}_{\mathrm{th}}-\mathrm{R}_{\mathrm{o}}
\end{gathered}
$$

The variation in values of $R_{A}$ and $R_{B}$ are given in Fig. 4 . Bond lengths $R_{A}$ and $R_{B}$ are increased with the substitution of $\mathrm{Ho}^{3+}$ ions.

SEM and TEM: Typical SEM and TEM images of the sample $x=0.4$ are shown in Fig. 5. It is observed from the SEM and TEM images that the prepared samples are amorphous and porous in nature with agglomeration.

Elastic properties: Elastic moduli and Debye temperature were determined through IR data and structural data of the series $\mathrm{Ni}_{0.2} \mathrm{Cu}_{0.2} \mathrm{Zn}_{0.6} \mathrm{Fe}_{2-\mathrm{x}} \mathrm{Ho}_{\mathrm{x}} \mathrm{O}_{4}$ ( $\mathrm{x}=0.0$ to 0.1 in steps of 0.02 ) ferrite samples [7]. The stiffness constant $\mathrm{C}_{11}$ was calculated using relation [8]:

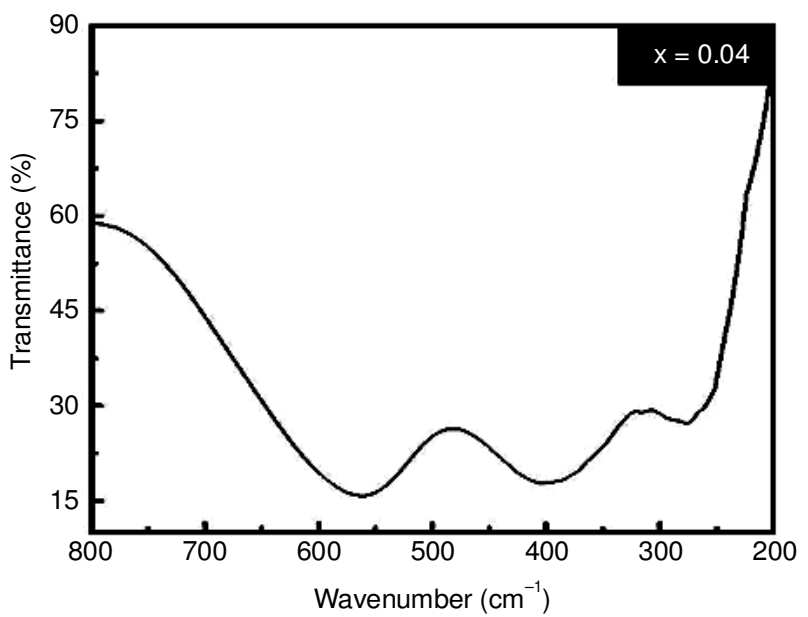

Fig. 3. Typical IR spectra $(x=0.02$ and $x=0.04)$ for the series 
TABLE-1

MEAN FORCE CONSTANT, POISSON'S RATIO, STIFFNESS CONSTANT AND DEBYE TEMPERATURE OF THE SERIES

\begin{tabular}{cccccc}
\hline $\begin{array}{c}\text { Comp. } \\
\mathrm{x}\end{array}$ & $\begin{array}{c}\text { Mean force } \\
\text { constant } \\
\mathrm{K} \times 10^{2}(\mathrm{~N} / \mathrm{m})\end{array}$ & $\begin{array}{c}\text { Poisson's } \\
\text { ratio } \sigma\end{array}$ & $\begin{array}{c}\mathrm{C}_{11} \\
(\mathrm{GPa})\end{array}$ & $\begin{array}{c}\mathrm{C}_{12} \\
(\mathrm{GPa})\end{array}$ & $\begin{array}{c}\text { Debye } \\
\text { temp. } \\
\theta_{\mathrm{E}}(\mathrm{K})\end{array}$ \\
\hline 0.00 & 1.360 & 0.276 & 161.562 & 61.594 & 506.847 \\
0.02 & 1.445 & 0.274 & 170.251 & 63.133 & 507.147 \\
0.04 & 1.434 & 0.272 & 171.634 & 63.597 & 508.611 \\
0.06 & 1.447 & 0.269 & 171.674 & 64.787 & 509.354 \\
0.08 & 1.762 & 0.266 & 184.758 & 65.073 & 510.361 \\
0.10 & 1.555 & 0.260 & 209.223 & 75.774 & 515.194 \\
\hline
\end{tabular}

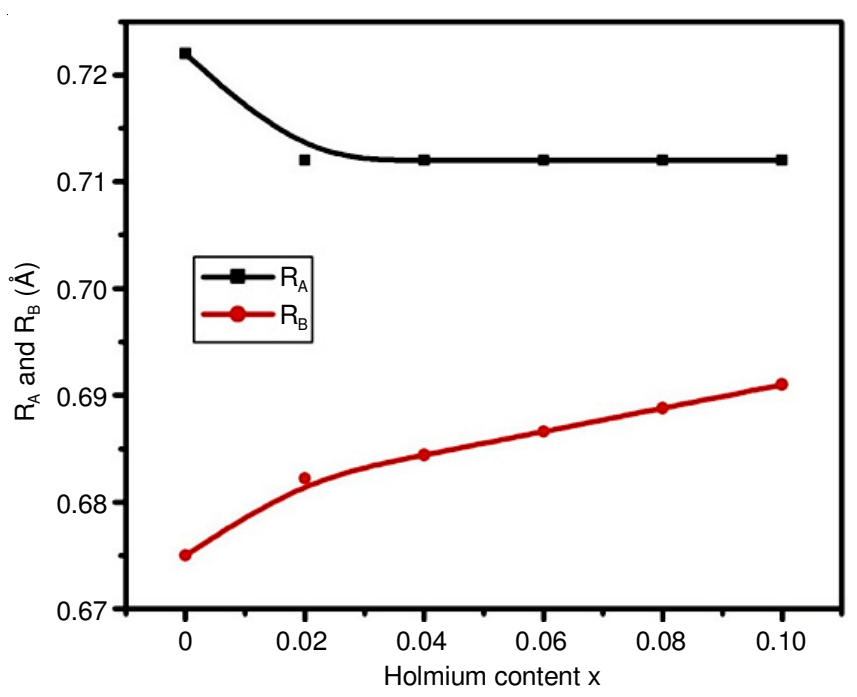

Fig. 4. Variation in values of $R_{A}$ and $R_{B}$ with holmium substitution

$$
\mathrm{C}_{11}=\frac{\mathrm{K}}{\mathrm{a}}
$$

where, $\mathrm{K}$ is average force constant and a is lattice constant.

$$
\left(C_{12}\right)=\frac{\sigma C_{11}}{(1-\sigma)}
$$

where, where $\sigma$ is Poisson's ratio and ' $a$ ' is the lattice constant. The Poisson's ratio is function of pore fraction. Using eqns, e and $f$ the stiffness constant is calculated and the variation is tabulated in Table-1. The variation in stiffness constant is illustrated in Fig. 6.

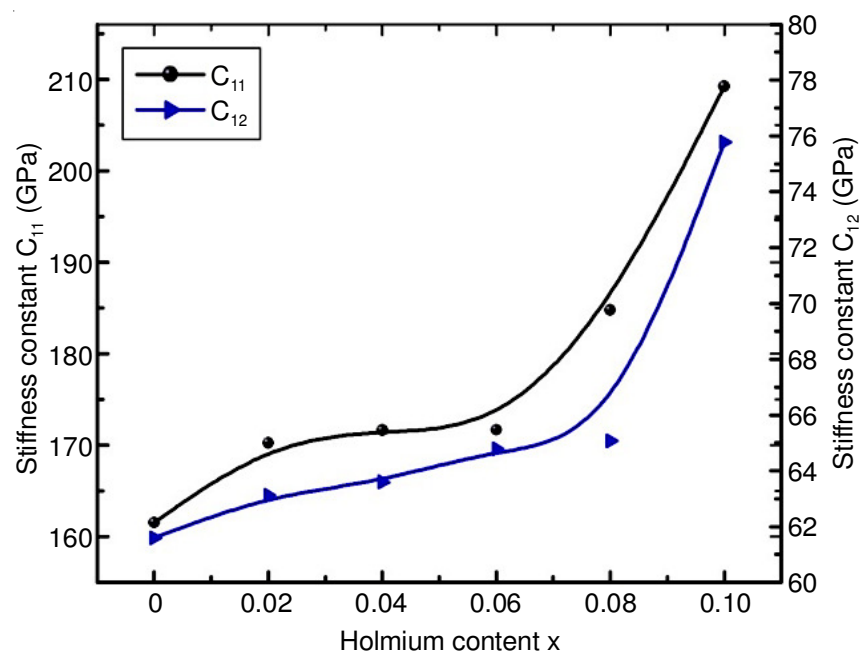

Fig. 6. Variation in stiffness constants with holmium content $\mathrm{x}$

It is observed from Table- 1 and Fig. 6 that both the stiffness constants were increases with increase in holmium substitution. The values of Poisson's ratio are decreased with the increasing holmium substitution. The various elastic constants such as; Young's modulus (E), bulk modulus $(\mathrm{K})$ and modulus of rigidity $(\mathrm{G})$ calculated using following equations [10]:

$$
\begin{gathered}
E=\frac{\left(C_{11}-C_{12}\right)\left(C_{11}+2 C_{12}\right)}{\left(C_{11}+C_{12}\right)} \\
K=\frac{1}{3}\left(C_{11}+2 C_{12}\right) \\
G=\frac{E}{2(\sigma+1)}
\end{gathered}
$$

The variation in Young's modulus (E), bulk modulus (K) and modulus of rigidity $(\mathrm{G})$ are presented in Table-1 and Fig.

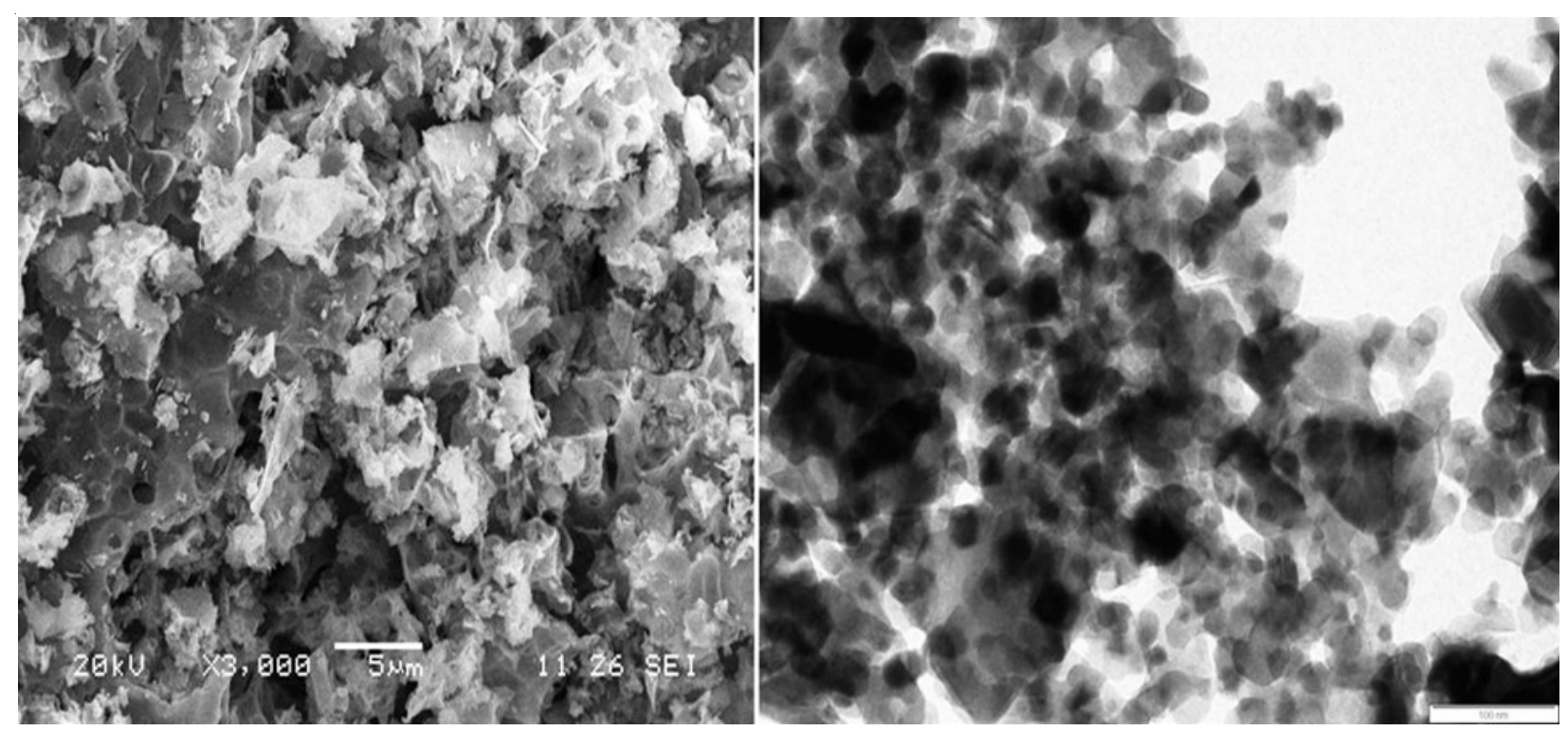

Fig. 5. SEM and TEM image of sample $(x=0.4)$ 
7. It can be observed that the values of Young's modulus (E), bulk modulus $(\mathrm{K})$ and modulus of rigidity $(\mathrm{G})$ increased with holmium substitution. This increase in elastic moduli correlated to the strengthening in interatomic bonding between iron and holmium ions with increase in holmium compo-sition $\mathrm{x}$.

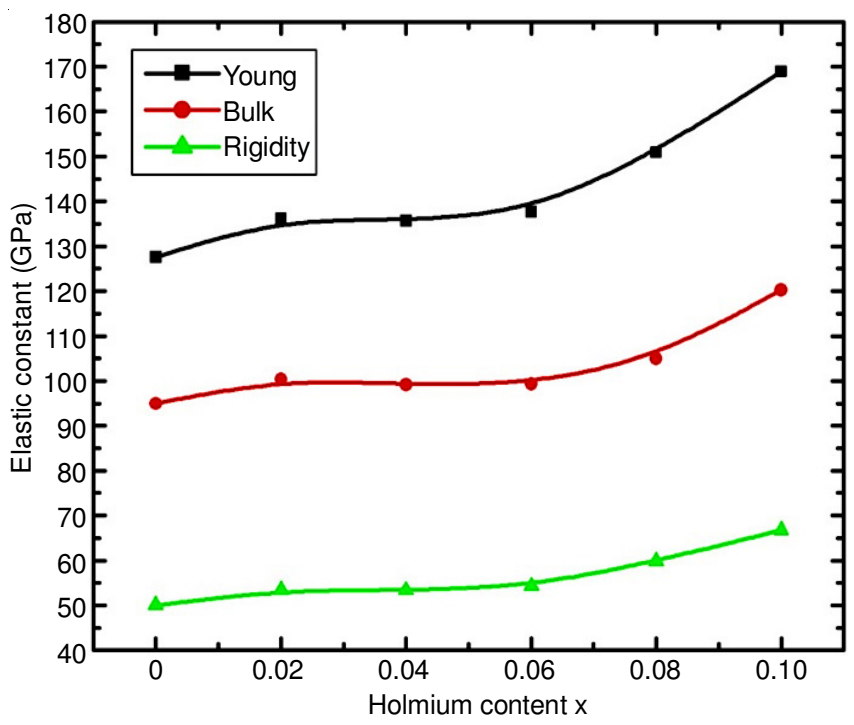

Fig. 7. Variation in elastic modulus with holmium content $\mathrm{x}$

The longitudinal wave velocity $\left(\mathrm{V}_{\mathrm{L}}\right)$ and Shearing wave velocity $\left(\mathrm{V}_{\mathrm{S}}\right)$ was calculated using following equations:

$$
\begin{aligned}
& \mathrm{V}_{\mathrm{L}}=\left(\frac{\mathrm{C}_{11}}{\rho}\right)^{1 / 2} \\
& \mathrm{~V}_{\mathrm{S}}=\left(\frac{\mathrm{G}}{\rho}\right)^{1 / 2}
\end{aligned}
$$

where, $\mathrm{G}$ is rigidity modulus with correct zero pore fraction. The values of $\mathrm{V}_{\mathrm{L}}$ and $\mathrm{V}_{\mathrm{s}}$ further used to determine mean wave velocity $\left(\mathrm{V}_{\mathrm{m}}\right)$ [10]. The variation in shearing velocity $\left(\mathrm{V}_{\mathrm{S}}\right)$, mean wave velocity $\left(\mathrm{V}_{\mathrm{m}}\right)$ and longitudinal wave velocity $\left(\mathrm{V}_{\mathrm{L}}\right)$ given in Table-1.

$$
\frac{3}{\mathrm{~V}_{\mathrm{m}}^{3}}=\frac{1}{\mathrm{~V}_{1}^{3}}+\frac{2}{\mathrm{~V}_{\mathrm{s}}^{3}}
$$

It is observed from Table-1 and Fig. 8 that the shearing velocity $\left(\mathrm{V}_{\mathrm{S}}\right)$, mean wave velocity $\left(\mathrm{V}_{\mathrm{m}}\right)$ and longitudinal wave velocity $\left(\mathrm{V}_{\mathrm{L}}\right)$ increased with holmium substitution. Debye temperature $\left(\theta_{\mathrm{E}}\right)$ was calculated using following equation [11]:

$$
\theta_{\mathrm{E}}=\frac{\mathrm{h}}{\mathrm{k}}\left(\frac{3 \rho \mathrm{qN}}{\mathrm{A}}\right)^{1 / 3} \times \mathrm{V}_{\mathrm{m}}
$$

where, $\mathrm{h}$ is planks constant, $\mathrm{k}$ is Boltzmann's constant, $\mathrm{M}$ is molecular weight, $\mathrm{q}$ is number of atom in the unit formula and $\mathrm{V}_{\mathrm{m}}$ mean wave velocity.

The variation of Debye temperature $\left(\theta_{\mathrm{E}}\right)$ is given Table- 1 . The Debye temperature (Fig. 9) increased with holmium substitution. Debye temperature corresponds to the temperature at which nearly all modes of vibration in solid are excited. Increased values of Debye temperature indicates the increase in the rigidity of nickel copper zinc ferrite with increase in holmium composition $\mathrm{x}$.

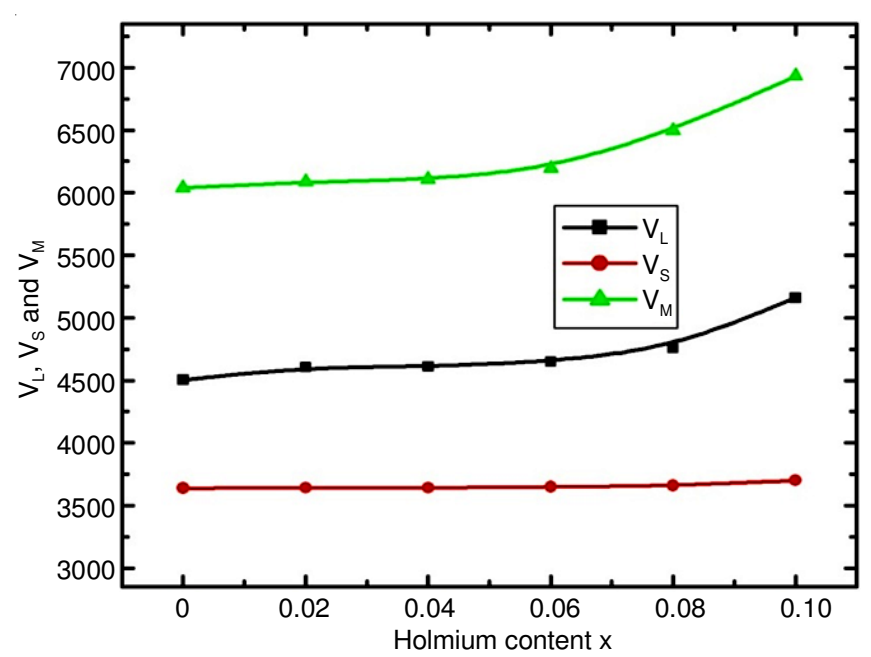

Fig. 8. Variation of shearing velocity $\left(\mathrm{V}_{\mathrm{S}}\right)$, mean wave velocity $\left(\mathrm{V}_{\mathrm{m}}\right)$ and longitudinal wave velocity $\left(\mathrm{V}_{\mathrm{L}}\right)$ with holmium content $\mathrm{x}$

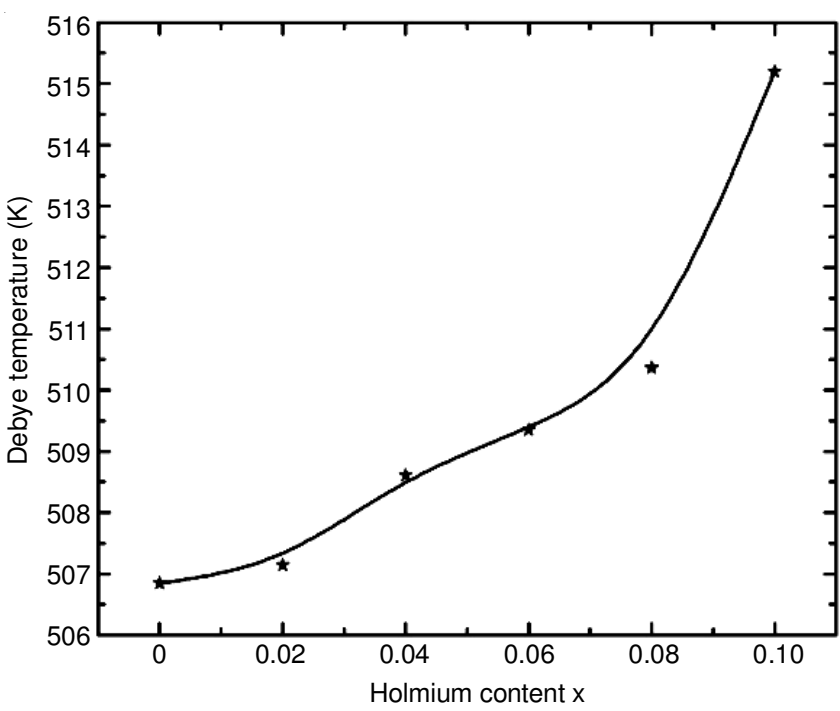

Fig. 9. Variation in Debye temperature with holmium content $x$

\section{Conclusion}

$\mathrm{Ni}_{0.2} \mathrm{Cu}_{0.2} \mathrm{Zn}_{0.6} \mathrm{Fe}_{2-\mathrm{x}} \mathrm{Ho}_{\mathrm{x}} \mathrm{O}_{4}$ ( $\mathrm{x}=0.0$ to 0.1 in steps of 0.02 ) synthesized by sol gel auto combustion method. High frequency bands $\left(574-563 \mathrm{~cm}^{-1}\right)$ assigned to the tetrahedral and low frequency bands $\left(438-364 \mathrm{~cm}^{-1}\right)$ assigned to the octahedral complex. It is observed from SEM and TEM images that the prepared samples are amorphous and porous in nature with agglomeration. The Poisson's ratio decreases with increase in holmium substitution. The values of Debye temperature, Young's modulus (E), bulk modulus $(\mathrm{K})$ and modulus of rigidity (G) and stiffness constant increased with holmium substitution. Increased values of Debye temperature indicated the increase in the rigidity of the nickel copper zinc ferrite with increase in holmium composition.

\section{REFERENCES}

1. M. Asif Iqbal, Misbah-ul-Islam, I. Ali, H.M. Khan, G. Mustafa and I. Ali, Ceram. Int., 39, 1539 (2013);

https://doi.org/10.1016/j.ceramint.2012.07.104

2. T. Abraham, Am. Ceram. Soc. Bull., 73, 62 (1994). 
3. S.R. Murthy, J. Mater. Sci. Lett., 21, 657 (2002); https://doi.org/10.1023/A:1015608625798.

4. M. Pardavi-Horvath, J. Magn. Magn. Mater, 215-216, 171 (2000); https://doi.org/10.1016/S0304-8853(00)00106-2.

5. T. Krishnaveni, B.R. Kanth, V.S.R. Raju and S.R. Murthy, J. Alloys Comp., 414, 282 (2006);

https://doi.org/10.1016/j.jallcom.2005.07.029.

6. B. Raj, V. Rajendran and P. Palanichamy, Science \& Technology of Ultrasonics, Narosa Publishing House, New Delhi, India (2004).

7. S.M. Patange, S.E. Shirsath, S.P. Jadhav, V.S. Hogade, S.R. Kamble and K.M. Jadhav, J. Mol. Struct., 1038, 40 (2013); https://doi.org/10.1016/j.molstruc.2012.12.053.
8. S.L. Kakani and C. Hemarajani, Text Book of Solid State Physics, Sultan Chand \& Son, New Delhi, India (1997).

9. E.W. Gorter, Philips Res. Rep., 9, 295 (1954).

10. S.E. Shirsath, S.M. Patange, R.H. Kadam, M.L. Mane and K.M. Jadhav, J. Mol. Struct., 1024, 77 (2012); https://doi.org/10.1016/j.molstruc.2012.05.014.

11. S.A. Mazen, S.F. Mansour, E. Dhahri, H.M. Zaki and T.A. Elmosalami, J. Alloys Comp., 470, 294 (2009); https://doi.org/10.1016/j.jallcom.2008.02.035. 